\title{
Current Approaches for the Non-surgical Management of Peri-implant Diseases
}

\author{
Andrea Roccuzzo ${ }^{1,2} \cdot$ Siro Pietro De Ry ${ }^{1} \cdot$ Anton Sculean ${ }^{1} \cdot$ Mario Roccuzzo ${ }^{3,4,5} \cdot$ Giovanni Edoardo Salvi $^{1}$
}

Published online: 30 July 2020

(C) The Author(s) 2020

\begin{abstract}
Purpose of the Review Peri-implant diseases are inflammatory reactions to bacterial infections affecting osseointegrated dental implants. In recent years, scientific interest on this topic has increased, as demonstrated by the appearance of a large number of protocols for treating peri-implant mucositis (PIM) and peri-implantitis (PI). The aim of the present narrative review is to provide an overview of the recent (e.g., 2014-present) published protocols for the non-surgical treatment of peri-implant diseases.

Recent Findings Several adjunctive measures for mechanical debridement have been proposed and investigated to achieve implant surface decontamination and resolution of mucosal inflammation. However, none of the adjunctive measures has been shown to significantly improve peri-implant conditions compared with non-surgical mechanical debridement alone.

Summary Non-surgical approaches for the treatment of peri-implant diseases have been proved to be reliable in reducing clinical signs of peri-implant inflammation (e.g., BoP), although with limited capability to achieve complete disease resolution. Due to the limited benefits from the use of currently proposed adjunctive methods (e.g., chlorhexidine, lasers, photodynamic therapy, systemic probiotics) their application is not recommended until further investigations prove their clinical utility.
\end{abstract}

Keywords Titanium $\cdot$ Dental implants $\cdot$ Peri-implant disease $\cdot$ Peri-implant mucositis $\cdot$ Peri-implantitis $\cdot$ Inflammation $\cdot$ Crestal bone loss

\section{Introduction}

The quality and reliability of implant supported oral rehabilitations of partially and totally edentulous patients have been radically increased during recent decades and feature high long-term implant survival and success rates $[1,2]$.

Andrea Roccuzzo and Siro Pietro De Ry contributed equally to this work.

This article is part of the Topical Collection on Peri-implantitis

Andrea Roccuzzo

andrea.roccuzzo@zmk.unibe.ch

1 Department of Periodontology, School of Dental Medicine, University of Bern, Freiburgstrasse 7, CH-3010 Bern, Switzerland

2 Department of Oral and Maxillo-Facial Surgery, Copenhagen University Hospital (Rigshospitalet), Copenhagen, Denmark

3 Department of Periodontics and Oral Medicine, University of Michigan, Ann Arbor, MI, USA

4 Torino, Italy

5 Division of Maxillo-facial Surgery, University of Torino, Torino, Italy
As reported at the World Workshop on the Classification of Periodontal and Peri-Implant Diseases and Conditions, periimplant health was defined at the clinical level by the absence of signs of soft tissue inflammation (e.g., BoP and suppuration) [3••]. Unfortunately, peri-implant diseases, namely, periimplant mucositis and peri-implantitis, occur. Over the years, several definitions have been applied to define peri-implant mucositis and peri-implantitis $[4,5]$. More recently, at the 2017 World Workshop on the Classification of Periodontal and Peri-Implant Diseases and Conditions, peri-implant mucositis and peri-implantitis definitions were adopted as follows $[6 \bullet \bullet, 7 \bullet \bullet, 8 \bullet \bullet]$ :

\section{Peri-implant Mucositis}

- The presence of bleeding and/or suppuration on gentle probing with or without increased probing depth compared with previous examinations

- The absence of bone loss beyond crestal bone level changes resulting from initial bone remodeling 
Visual signs of inflammation may vary, and peri-implant mucositis may be present around implants with variable levels of bone support.

\section{Peri-implantitis}

- The presence of bleeding and/or suppuration on gentle probing

- Increased probing depth compared with previous examinations

- The presence of bone loss beyond crestal bone level changes resulting from initial bone remodeling

\section{Prevalence of Peri-implant Diseases}

The world-wide prevalence of peri-implant diseases has been widely investigated: a systematic review of the literature reported a prevalence of peri-implant mucositis of $43 \%$ (range $19-65 \%$ ) and peri-implantitis of $22 \%$ (range 1-47\%) [9]. More recently, several data from cross-sectional studies have been published, assessing the frequency of peri-implantitis between 13 and 26\% [10-14]. However, due to the present wide range of reported prevalences reflecting the high heterogeneity of the applied clinical and radiographic thresholds of disease definition, an adequate estimate of these diseases is difficult [9]. Nonetheless, despite the variety of definitions applied to detect these two clinical scenarios, the interest on this topic has markedly increased during the last decade, as shown by the high number of systematic reviews published [15-19]. The first approach for the treatment of peri-implant diseases has evolved from the classic periodontal treatment including scaling and root planing to interventions aiming at removing the peri-implant biofilm and granulation tissue [20]. The first diagnostic and therapeutic steps to manage periimplant diseases were summarized more than 20 years ago by Lang and co-workers who proposed the Cumulative Interceptive Supportive Therapy (CIST) protocol [21]. This cumulative protocol includes a sequence of non-surgical interventions (A: mechanical debridement, B: antiseptic therapy, C: antibiotic therapy) followed by surgical procedures (D) and explantation as the last therapeutic step (E). Despite the application of several different treatment modalities, a huge discrepancy between the efficacy of non-surgical therapy around teeth compared with that around dental implants has been reported [20]. Nonetheless, it has been widely accepted that clinicians should attempt to deliver non-surgical interventions around dental implants prior to surgery.

The aim of the present narrative review was to summarize the most recent scientific evidence (2014-present) published on the non-surgical treatment of peri-implant diseases.
Clinical Approaches to Manage Peri-Implant Mucositis

Due to the reversible nature of peri-implant mucositis [22••, $23,24 \cdot]$, the proposed treatment strategies to manage soft tissue inflammation rely on the paradigm of infection control. More specifically, to reduce the overall bacterial load under a specific threshold, the following three key steps have been investigated:

\section{Peri-implant Biofilm Removal}

Historically, peri-implant surface decontamination has been performed by a combination of hand (i.e., titanium, plastic, Teflon, carbon-fiber) [25••] and mechanical (i.e., abrasive airpowder systems, rubber cup) instruments with conflicting results on the superiority of one versus another modality [26]. These results were corroborated by a large 6-month comparative multicenter study on 141 implants, which failed to detect any statistically significant difference in terms of reduction of mucosal inflammation (i.e., BoP change) among the four investigated tools (i.e., sonic plastic tips, titanium curettes, airflow with glycine powder or rubber cups and polishing paste) [27].

Different results were reported by another group, which compared the efficacy of air-abrasive glycine powder to manual debridement performed with plastic curettes followed by local irrigation with a $0.1 \%$ chlorexidine digluconate solution around 88 implants. At the 6-month follow-up, a statistically significant difference between the two groups with respect to mean probing depth (PD) (1.87 SD 0.38 vs. $2.70 \mathrm{SD} 0.37)$ and BoP (20.83 SD 30.99 vs. 70.45 SD 26.32) in favor of the airpolishing device was observed [28].

Riben-Grundström and coworkers compared the application of a glycine powder air-polishing device to an ultrasonic instrument with a plastic coated tip to decontaminate $36 \mathrm{im}$ plants with 3 different surfaces. At the 12-month evaluation, similar changes in both the percentages of sites with $\mathrm{PD} \geq 4 \mathrm{~mm}$ and BoP positive were reported. Therefore, the authors concluded that both devices were "effective in reducing inflammation and number of peri-implant pockets" eventhough complete disease resolution was difficult to achieve in both groups [29].

More recently, the efficacy of a chitosan brush to debride peri-implant surfaces characterized by clinical signs of inflammation (i.e., PPD $\geq 4 \mathrm{~mm}$ with concomitant $\mathrm{BoP}$ and no detectable marginal bone loss) was compared with titanium curettes in a split mouth 6-month randomized clinical trial (RCT). A statistically significant difference in favor of the chitosan brush was detected only in the early healing phase (i.e., at week 2 and 4), while at the 6-month follow-up this benefit was not observed [30]. 
Adjuncts to Implant Surface Disinfection (i.e., Laser, Sodium Hypochlorite, Chlorexidine, Probiotics, Enamel Matrix Derivative)

Due the difficulties in removing peri-implant biofilms and properly decontaminating implant surfaces, several adjunctive agents have been recently released to the dental market. In particular, the antibacterial [31] and decontamination [32] effects of a diode laser have been reported both in vitro and in vivo studies. Similar results have been reported in a retrospective study including 27 patients rehabilitated with 125 dental implants treated with a combined protocol (i.e., mechanical debridement, diode laser application followed by a local chlorexidine gel application). A statistically significant difference $(p<0.0001)$ with respect to mean PD reduction was detected between test (2.66 SD $1.07 \mathrm{~mm}$ ) and control (0.94 SD $1.13 \mathrm{~mm}$ ) groups as well as the final percentages of sites with BoP (T: 4.95\%, C: 59.72\%). The present results should be carefully interpreted due to the study design including different sample sizes between tests and controls and imbalance for potential confounding factors such as smoking. Moreover, due to the local application of chlorexidine gel, the adjunctive benefits of diode laser itself seems difficult to be estimated [33]. These positive findings could not be replicated in a recent study by Aimetti and co-workers who reported the outcomes of a 3-month RCT. A $3 \times$ diode laser application as an adjunctive treatment of 220 implants did not yield any statistically significant clinical benefits compared with mechanical debridement alone [34•0]. Therefore, at the present time, eventhough adjunctive application of laser might result in greater BoP reduction in the short-term, due to the lack of long-term data, its routinely use to manage peri-implant mucositis seems unjustified [35•*].

The use of a sodium hypochlorite $(\mathrm{NaOCl})$ gel was recently investigated by Iorio-Siciliano and co-workers as an adjunct to mechanical debridement alone in the management of periimplant mucositis. More specifically, in a 6-month triple blind $\mathrm{RCT}$ it was reported that a $5 \times$ application for $30 \mathrm{~s}$ of $\mathrm{NaOCl}$ gel prior to mechanical debridement with an ultrasonic scaler failed to statistically significantly improve PD and BoP reductions compared with mechanical debridement alone. Moreover, the results indicated that a complete resolution of mucosal inflammation was achieved in $45 \%$ of test and $32 \%$ of control implants, respectively [36॰].

The use of chlorexidine as chemical adjunct to enhance biofilm control in conjunction with non-surgical periodontal therapy has been widely assessed $[37,38]$. Consequently, its application on affected dental implants have been investigated. Recently, a $0.12 \%$ chlorexidine gluconate solution was applied into the periimplant pockets after mechanical debridement performed with plastic curettes [39]. In addition, the 22 patients diagnosed with 61 implants affected by peri-implant mucositis were prescribed twice daily for 2 weeks chlorhexidine mouth rinses. At the 6month evaluation, no clinical difference between the antiseptic and placebo solution was detected with respect to the number of BoP positive sites [39].

On the other hand, the clinical benefits of a single daily session of oral hygiene procedure with adjunctive $0.2 \%$ chlorhexidine gel were reported in a 12-week RCT. The 19 test patients displayed after 4 and 12 weeks a statistically significantly lower percentage of residual pockets ( $\mathrm{PD} \geq 4 \mathrm{~mm}$ ) compared with the 18 controls ( $33 \%$ vs. $55 \%, p<0.05)$ despite the fact that one third of the implants was still $\mathrm{BoP}$ positive at the final evaluation [40].

A solution containing chlorexidine $0.03 \%+0.05 \%$ cetylpyridinium chloride was recently tested over a 1 -year period as an adjunct in the treatment of peri-implant mucositis [41]. The rationale behind the use of this solution originates from the successful management of gingivitis [42] associated with reduced side effects of a pure chlorhexidine rinse [43]. At the 12-month follow-up, the twice daily tested solution was not more effective than the placebo rinse for most of the assessed clinical parameters except for the changes in buccal BoP values $(47 \%$ vs. $23 \%)(p=$ 0.022). Once more the authors underlined that complete BoP resolution was achieved in 58\% of the test cases [41].

Among the adjunctive means to manage peri-implant mucositis, the use of probiotics has been advocated based on their delivery in non-surgical periodontal therapy $[44,45]$. In particular, Flichy-Fernández and co-workers reported the positive effects provided by the adjunctive delivery of tablets containing Lactobacillus reuteri (dosage: $1 \times 30$ days) on 23 implants diagnosed with peri-implant mucositis [46]. Adjunctive probiotics delivery yielded an additional PD reduction of $1.09 \mathrm{SD} 0.90 \mathrm{~mm}$ compared with the placebo group after 6 months. However, these results should be interpreted with caution because BoP values as the primary outcome of periimplant mucositis therapy were not reported. On the other hand, the present results were not corroborated by recent RTCs, which failed to document the effects of adjunctive probiotics in the treatment of peri-implant mucositis [47, 48].

Furthermore, following the promising results obtained by Froum et al. 2012 [49] on the use of enamel matrix derivatives (EMD) as an adjunct in the treatment of peri-implantitis, Kashefimehr et al. (2017) evaluated the use of EMD around dental implants diagnosed with peri-implant mucositis. Following submucosal mechanical debridement, adjunctive EMD application yielded statistically significantly shallower PDs (median 3.0 vs. $5.0 \mathrm{~mm}$ ) as well as lower BoP percentages (25\% vs. $75.0 \%$ ) at the 3-month follow-up [50]. The mean findings from the discussed studies are summarized in Table 1.

\section{Patient-Administered Oral Hygiene Procedures}

In addition to professionally administered mechanical and adjunctive procedures, optimal patient-administered biofilm control regimes are crucial in the management of peri-implant mucositis. 


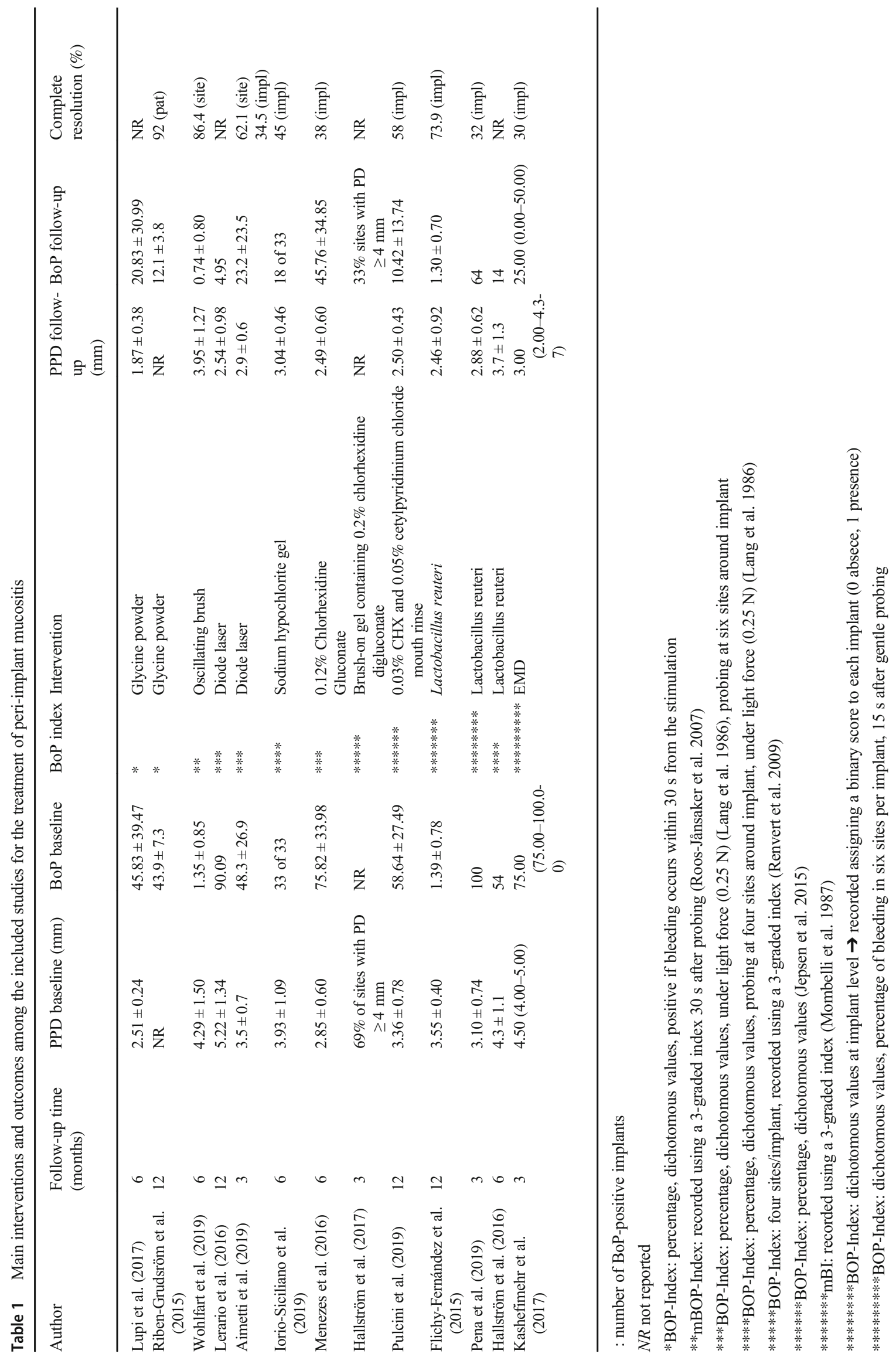


Nonetheless, the evidence of the superiority of powered vs. manual tooth brushes as well as the efficacy of twice daily patient's administered antiseptic rinse seem to be negligible [51•]. Moreover, the application of a chlorexidine gel failed to provide clear benefits in the management of peri-implant soft tissue inflammation [52]. Finally, even-though systemic delivery of azythromycin might result in better clinical outcomes when compared with the mechanical debridement alone [53], its use seems unjustified to manage peri-implant mucositis $[51 \bullet]$.

\section{Clinical Approaches to Manage Peri-Implantitis}

Due to the irreversible nature of peri-implantitis, characterized by progressive marginal bone loss, the non-surgical interventions are based on the following steps:

\section{Peri-implant Biofilm Removal}

Mechanical decontamination methods of the implant surface have been pointed out to be crucial in order to achieve resolution of mucosal inflammation. However, due to several differences between teeth and dental implants (i.e., macro and micro characteristics of the implant surface), debriding and decontaminating peri-implant surfaces are more challenging than those around teeth. Therefore, various tools have been introduced into the market to debride peri-implant surfaces. In particular, a new oscillating chitosan brush was tested in a 6-month single-group multi-center study including 63 patients diagnosed with initial peri-implantitis. Although the results indicated statistically significant improvements of PD and BoP scores between baseline and follow-up, due to the lack of a control group no definitive conclusions could be drawn [54]

An additional study protocol compared the efficacy of monotherapy with an air-polishing device containing glycine powder with mechanical debridement with carbon fiber curettes and chlorhexidine digluconate after 12 months [55]. At the final evaluation, no statistically significant differences were found between the groups with respect to plaque index, $\mathrm{PD}$, mucosal recession, and clinical attachment level, while lower BoP values were detected in the air-polishing group.

Currently, besides the multitude of methods proposed for the mechanical debridement of implant surfaces, there is little research investigating the efficacy of such devices. Therefore, no clear clinical recommendations can be provided on which tool should be selected to accomplish professional mechanical debridement around dental implants.

\section{Adjuncts to Mechanical Debridement (i.e., Lasers, Photodynamic Therapy, Sodium Hypochlorite)}

Although potential benefits of photodynamic and laser therapy on implants affected by peri-implantitis were reported [56], conflicting results on their use as an adjunct to mechanical debridement are available [57••].

In a single cohort retrospective study involving 15 subjects with 23 implants with a sand-blasted and acid etched (SLA) surface, Mettraux et al. (2016) reported promising 2-year results in terms of $\mathrm{PD}$ and suppuration reduction despite the fact that complete resolution of inflammation was not achieved, as shown by $43 \%$ of sites still BoP positive [58]. Similar results were reported by Bassetti and co-workers who performed a 12month RCT to test the adjunctive benefits of a $2 \times$ PDT application. In particular, the test group failed to show any statistically significant difference of BoP scores compared with controls treated with minocycline hydrochloride microspheres (1.74 SD 1.37 vs. 1.55 SD1.26) [59].

The adjunctive benefits of a sodium hypochlorite solution (Perisolv ${ }^{\circledR}$ ) to mechanical debridement alone was tested in a RCT with a split-mouth design including sixteen patients [60]. At the 3-month evaluation, significant improvements in terms of BoP positive sites as well as PD reduction were observed in both groups when compared with baseline. Nonetheless, since no statistically significant difference was detected between groups, it was concluded that mechanical debridement with adjunctive use of sodium hypochlorite was equally effective in the reduction of mucosal inflammation as conventional non-surgical mechanical debridement alone.

One of the most challenging aspects in the evaluation of the efficacy of a specific treatment protocol is that a combined mechanical and chemical intervention is investigated. Recently, in a 12-month retrospective case series, significant improvements in terms of $\mathrm{PD}$ and BoP reductions and radiographic bone gain were reported following repeated applications of a combined approach including mechanical debridement, subgingival chlorhexidine irrigation, and systemic antibiotics [61]. Although the application of a combined nonsurgical protocol yielded positive outcomes at 1 year, the lack of a control group failed to reveal superiority of this treatment modality compared with mechanical debridement alone [61]. Studies details are reported in Table 2.

\section{Limitations}

The evidence summarized in the analyzed literature presents several major limitations making comparisons among studies difficult. 
First, a homogeneous case-definition of peri-implant mucositis and a highly heterogeneous definition of peri-implantitis were detected. Second, despite the fact that most of the studies reported a power calculation, the question of what should be considered the primary outcome measure in the management of peri-implant mucositis (i.e., BoP or PD change) is still a matter of debate. In addition, in most of the studies the role of implant surface characteristics was not considered since several implant systems with different surface roughnesses were treated. Finally, despite increasing evidence underlying the importance of an adequate width (i.e., $\geq 2 \mathrm{~mm}$ ) of keratinized and attached peri-implant soft tissue seal $[62 \cdot]$, the characteristics of the soft tissue conditions were poorly reported in the included studies.

\section{Conclusions}

Based on the level of evidence of the last 5 years, nonsurgical approaches in the management of peri-implant diseases have been shown to be effective in reducing signs of bleeding on probing even-though complete resolution of inflammation still remains unpredictable. On the other hand, in cases of advanced peri-implant lesions, the use of non-surgical protocols should aim at preparing healthier soft tissue conditions prior to adjunctive therapy including reconstructive and resective surgery. Finally, patient's enrolment in a tailored supportive therapy program seems crucial to monitoring peri-implant conditions before and after treatment.

Funding Information Open access funding provided by University of Bern. The study was self-funded and no external funding was received by any of the authors. Andrea Roccuzzo is the recipient of a 3-year scholarship from the Clinical Research Foundation (CFR) for the Promotion of Oral Health, Brienz, Switzerland.

\section{Compliance with Ethical Standards}

Conflict of Interest The authors declare that they have no conflict of interest.

Informed Consent To perform the present study, informed consent was not required.

Open Access This article is licensed under a Creative Commons Attribution 4.0 International License, which permits use, sharing, adaptation, distribution and reproduction in any medium or format, as long as you give appropriate credit to the original author(s) and the source, provide a link to the Creative Commons licence, and indicate if changes were made. The images or other third party material in this article are included in the article's Creative Commons licence, unless indicated otherwise in a credit line to the material. If material is not included in the article's Creative Commons licence and your intended use is not permitted by statutory regulation or exceeds the permitted use, you will need to obtain permission directly from the copyright holder. To view a copy of this licence, visit http://creativecommons.org/licenses/by/4.0/. 


\section{References}

Papers of particular interest, published recently, have been highlighted as:

- Of importance

- Of major importance

1. Buser D, Janner SFM, Wittneben JG, Brägger U, Ramseier CA, Salvi GE. 10-year survival and success rates of 511 titanium implants with a sandblasted and acid-etched surface: a retrospective study in 303 partially edentulous patients. Clin Implant Dent Relat Res. 2012;14:83951. https://doi.org/10.1111/j.1708-8208.2012.00456.x.

2. Howe M-S, Keys W, Richards D. Long-term (10-year) dental implant survival: a systematic review and sensitivity meta-analysis. J Dent. 2019;84:9-21. https://doi.org/10.1016/j.jdent.2019.03.008.

3.• Araujo MG, Lindhe J. Peri-implant health. J Clin Periodontol. 2018;45:S230-6. https://doi.org/10.1111/jcpe.12952. This paper reports on the 2017 EFP-AAP World Worshop.

4. Lindhe J, Meyle J. Peri-implant diseases: consensus report of the sixth European workshop on periodontology. J Clin Periodontol. 2008;35: 282-5. https://doi.org/10.1111/j.1600-051X.2008.01283.x.

5. Sanz M, Chapple IL. Clinical research on peri-implant diseases: consensus report of working group 4. J Clin Periodontol. 2012;39:202-6. https://doi.org/10.1111/j.1600-051X.2011.01837.x.

6.• Heitz-Mayfield LJA, Salvi GE. Peri-implant mucositis. J Periodontol. 2018;89:S257-66. https://doi.org/10.1002/JPER.16-0488. This paper reports on the 2017 EFP-AAP World Worshop.

7.• Schwarz F, Derks J, Monje A, Wang HL. Peri-implantitis. J Clin Periodontol. 2018;45:S246-66. https://doi.org/10.1111/jcpe. 12954. This paper reports on the 2017 EFP-AAP World Worshop.

8.• Berglundh T, Armitage G, Araujo MG, Avila-Ortiz G, Blanco J, Camargo PM, et al. Peri-implant diseases and conditions: consensus report of workgroup 4 of the 2017 World Workshop on the Classification of Periodontal and Peri-Implant Diseases and Conditions. J Clin Periodontol. 2018;45:S286-91 https://doi.org/ 10.1111/jcpe.12957. This paper reports on the 2017 EFP-AAP World Worshop.

9. Derks J, Tomasi C. Peri-implant health and disease. A systematic review of current epidemiology. J Clin Periodontol. 2015;42:S158 71. https://doi.org/10.1111/jcpe.12334.

10. Aguirre-Zorzano LA, Estefanía-Fresco R, Telletxea O, Bravo M. Prevalence of peri-implant inflammatory disease in patients with a history of periodontal disease who receive supportive periodontal therapy. Clin Oral Implants Res. 2015;26:1338-44. https://doi.org/ 10.1111/clr.12462.

11. Daubert DM, Weinstein BF, Bordin S, Leroux BG, Flemmig TF. Prevalence and predictive factors for peri-implant disease and implant failure: a cross-sectional analysis. J Periodontol. 2015;86: 337-47. https://doi.org/10.1902/jop.2014.140438.

12. Konstantinidis IK, Kotsakis GA, Gerdes S, Walter MH. Crosssectional study on the prevalence and risk indicators of periimplant diseases. Eur J Oral Implantol. 2015;8:75-88 [internet]. Available from: http://www.ncbi.nlm.nih.gov/pubmed/25738181.

13. Dalago HR, Schuldt Filho G, Rodrigues MAP, Renvert S, Bianchini MA. Risk indicators for Peri-implantitis. A crosssectional study with 916 implants. Clin Oral Implants Res. 2017;28:144-50. https://doi.org/10.1111/clr.12772.

14. Schwarz F, Becker K, Sahm N, Horstkemper T, Rousi K, Becker J. The prevalence of peri-implant diseases for two-piece implants with an internal tube-in-tube connection: a cross-sectional analysis of 512 implants. Clin Oral Implants Res. 2017;28:24-8. https://doi. org/10.1111/clr.12609.
15. Esposito M, Grusovin MG, Worthington HV. Treatment of periimplantitis: what interventions are effective? A Cochrane systematic review. Eur J Oral Implantol. 2012;5(Suppl):S21-41.

16. Muthukuru M, Zainvi A, Esplugues EO, Flemmig TF. Nonsurgical therapy for the management of peri-implantitis: a systematic review. Clin Oral Implants Res. 2012;23:77-83. https://doi. org/10.1111/j.1600-0501.2012.02542.x.

17. Schwarz F, Schmucker A, Becker J. Efficacy of alternative or adjunctive measures to conventional treatment of peri-implant mucositis and peri-implantitis: a systematic review and meta-analysis. Int J Implant Dent. 2015;1:22. https://doi.org/10.1186/s40729-015-0023-1.

18. Schwarz F, Becker K, Sager M. Efficacy of professionally administered plaque removal with or without adjunctive measures for the treatment of peri-implant mucositis. A systematic review and metaanalysis. J Clin Periodontol. 2015;42:S202-13. https://doi.org/10. 1111/jcpe. 12349.

19. Suárez-López del Amo F, Yu S-H, Wang H-L. Non-surgical therapy for peri-implant diseases: a systematic review. J Oral Maxillofac Res. 2016;7:1-14. https://doi.org/10.5037/jomr.2016.7313.

20. Lang NP, Salvi GE, Sculean A. Nonsurgical therapy for teeth and implants — when and why? Periodontol. 2019;79:15-21. https:// doi.org/10.1111/prd.12240.

21. Lang NP, Mombelli A, Tonetti MS, Brägger U, Hämmerle CHF. Clinical trials on therapies for peri-implant infections. Ann Periodontol. 1997;2:343-56. https://doi.org/10.1902/annals.1997.2.1. 343.

22.• Salvi GE, Aglietta M, Eick S, Sculean A, Lang NP, Ramseier CA. Reversibility of experimental peri-implant mucositis compared with experimental gingivitis in humans. Clin Oral Implants Res. 2012;23:182-90. https://doi.org/10.1111/j.1600-0501.2011.02220. $\mathrm{x}$. This study provides evidence on the reversibility of periimplant mucositis in humans.

23. Meyer S, Giannopoulou C, Courvoisier D, Schimmel M, Müller F, Mombelli A. Experimental mucositis and experimental gingivitis in persons aged 70 or over. Clinical and biological responses. Clin Oral Implants Res. 2017;28:1005-12. https://doi.org/10.1111/clr.12912.

24. Chan D, Pelekos G, Ho D, Cortellini P, Tonetti MS. The depth of the implant mucosal tunnel modifies the development and resolution of experimental peri-implant mucositis: a case-control study. J Clin Periodontol. 2019;46:248-55. https://doi.org/10.1111/jcpe.13066. This study provides evidence on the influence of the implantabutment connection for the development o fperi-implant mucositis.

25.• Jepsen S, Berglundh T, Genco R, Aass AM, Demirel K, Derks J, et al. Primary prevention of peri-implantitis: managing peri-implant mucositis. J Clin Periodontol. 2015;42:S152-7. https://doi.org/10. 1111 jepe.12369. This review summarizes the evidence on the management of peri-implant mucositis.

26. Figuero E, Graziani F, Sanz I, Herrera D, Sanz M. Management of peri-implant mucositis and peri-implantitis. Periodontol. 2014;66: 255-73. https://doi.org/10.1111/prd.12049.

27. Blasi A, Iorio-Siciliano V, Pacenza C, Pomingi F, Matarasso S, Rasperini G. Biofilm removal from implants supported restoration using different instruments: a 6-month comparative multicenter clinical study. Clin Oral Implants Res. 2016;27:e68-73. https:// doi.org/10.1111/clr.12530.

28. Lupi SM, Granati M, Butera A, Collesano V, Rodriguez Y, Baena R. Air-abrasive debridement with glycine powder versus manual debridement and chlorhexidine administration for the maintenance of periimplant health status: a six-month randomized clinical trial. Int J Dent Hyg. 2017;15:287-94. https://doi.org/10.1111/idh.12206.

29. Riben-Grundstrom C, Norderyd O, André U, Renvert S. Treatment of peri-implant mucositis using a glycine powder air-polishing or ultrasonic device: a randomized clinical trial. J Clin Periodontol. 2015;42:462-9. https://doi.org/10.1111/jcpe.12395. 
30. Wohlfahrt JC, Aass AM, Koldsland OC. Treatment of peri-implant mucositis with a chitosan brush - a pilot randomized clinical trial. Int J Dent Hyg. 2019;17:170-6. https://doi.org/10.1111/idh.12381.

31. Deppe $\mathrm{H}$, Horch $\mathrm{H}-\mathrm{H}$, Neff A. Conventional versus $\mathrm{CO} 2$ laserassisted treatment of peri-implant defects with the concomitant use of pure-phase beta-tricalcium phosphate: a 5-year clinical report. Int J Oral Maxillofac Implants. 2019;22:79-86.

32. Bach G, Neckel C, Mall C, Krekeler G. Conventional versus laserassisted therapy of periimplantitis: a five-year comparative study. Implant Dent. 2000;9:247-51.

33. Lerario F, Roncati M, Gariffo A, Attorresi E, Lucchese A, Galanakis A, et al. Non-surgical periodontal treatment of periimplant diseases with the adjunctive use of diode laser: preliminary clinical study. Lasers Med Sci. 2016;31:1-6. https://doi.org/10. 1007/s10103-015-1785-7.

34.• Aimetti M, Mariani GM, Ferrarotti F, Ercoli E, Liu CC, Romano F. Adjunctive efficacy of diode laser in the treatment of peri-implant mucositis with mechanical therapy: a randomized clinical trial. Clin Oral Implants Res. 2019;30:429-38. https://doi.org/10.1111/clr. 13428. This study provides evidence on the lack of adjunctive benefit of diode laser application to treat peri-implant mucositis.

35.• Lin G-H, Suárez López Del Amo F, Wang H-L. Laser therapy for treatment of peri-implant mucositis and peri-implantitis: aan American Academy of Periodontology best evidence review. J Periodontol. 2018;89:766-82. https://doi.org/10.1902/jop.2017.160483. This position paper provides evidence on lack of adjunctive benefit of lasers on the treatment of peri-implant diseases.

36. Iorio-Siciliano V, Blasi A, Stratul S-I, Ramaglia L, Sculean A, Salvi GE, et al. Anti-infective therapy of peri-implant mucositis with adjunctive delivery of a sodium hypochlorite gel: a 6-month randomized triple-blind controlled clinical trial. Clin Oral Investig. 2019;24:1971-9. https://doi.org/10.1007/s00784-019-03060-2. This paper provides evidence on the lack od adjanctive benefit of sodum hypoclorite to treat peri-implant mucositis.

37. Berchier CE, Slot DE, Van Der Weijden GA. The efficacy of $0.12 \%$ chlorhexidine mouthrinse compared with $0.2 \%$ on plaque accumulation and periodontal parameters: a systematic review. J Clin Periodontol. 2010;37:829-39. https://doi.org/10.1111/j.1600051X.2010.01575.x.

38. Gunsolley JC. Clinical efficacy of antimicrobial mouthrinses. J Dent. 2010;38:S6-S10. https://doi.org/10.1016/S0300-5712(10)70004-X.

39. Menezes KM, Fernandes-Costa AN, Silva-Neto RD, Calderon PS, Gurgel BCV. Efficacy of $0.12 \%$ Chlorhexidine gluconate for nonsurgical treatment of peri-implant mucositis. J Periodontol. 2016;87:1305-13. https://doi.org/10.1902/jop.2016.160144.

40. Hallström H, Lindgren S, Twetman S. Effect of a chlorhexidinecontaining brush-on gel on peri-implant mucositis. Int J Dent Hyg. 2017;15:149-53. https://doi.org/10.1111/idh.12184.

41. Pulcini A, Bollaín J, Sanz-Sánchez I, Figuero E, Alonso B, Sanz M, et al. Clinical effects of the adjunctive use of a $0.03 \%$ chlorhexidine and $0.05 \%$ cetylpyridinium chloride mouth rinse in the management of peri-implant diseases: a randomized clinical trial. J Clin Periodontol. 2019;46:342-53. https://doi.org/10.1111/jcpe.13088.

42. Escribano M, Herrera D, Morante S, Teughels W, Quirynen M, Sanz M. Efficacy of a low-concentration chlorhexidine mouth rinse in noncompliant periodontitis patients attending a supportive periodontal care programme: a randomized clinical trial. J Clin Periodontol. 2010;37: 266-75. https://doi.org/10.1111/j.1600-051X.2009.01521.x.

43. Smith RG, Moran J, Addy M, Doherty F, Newcombe RG. Comparative staining in vitro and plaque inhibitory properties in vivo of $0.12 \%$ and $0.2 \%$ chlorhexidine mouthrinses. J Clin Periodontol. 1995;22:613-1. https://doi.org/10.1111/j.1600-051x. 1995.tb00814.x.

44. Teughels W, Loozen G, Quirynen M. Do probiotics offer opportunities to manipulate the periodontal oral microbiota? J Clin
Periodontol. 2011;38:159-77. https://doi.org/10.1111/j.1600051X.2010.01665.x.

45. Martin-Cabezas R, Davideau J-L, Tenenbaum H, Huck O. Clinical efficacy of probiotics as an adjunctive therapy to non-surgical periodontal treatment of chronic periodontitis: a systematic review and meta-analysis. J Clin Periodontol. 2016;43:520-30. https://doi.org/ 10.1111/jcpe. 12545.

46. Flichy-Fernández AJ, Ata-Ali J, Alegre-Domingo T, Candel-Martí E, Ata-Ali F, Palacio JR, et al. The effect of orally administered probiotic lactobacillus reuteri-containing tablets in peri-implant mucositis: a double-blind randomized controlled trial. J Periodontal Res. 2015;50:775-85. https://doi.org/10.1111/jre.12264.

47. Hallström H, Lindgren S, Widén C, Renvert S, Twetman S. Probiotic supplements and debridement of peri-implant mucositis: a randomized controlled trial. Acta Odontol Scand. 2016;74:60-6. https://doi.org/10.3109/00016357.2015.1040065.

48. Peña M, Barallat L, Vilarrasa J, Vicario M, Violant D, Nart J. Evaluation of the effect of probiotics in the treatment of periimplant mucositis: a triple-blind randomized clinical trial. Clin Oral Investig. 2019;23:1673-83. https://doi.org/10.1007/s00784018-2578-8.

49. Froum SJ, Froum SH, Rosen PS. Successful management of periimplantitis with a regenerative approach: a consecutive series of 51 treated implants with 3- to 7.5-year follow-up. Int J Periodontics Restorative Dent. 2012;32:11-20.

50. Kashefimehr A, Pourabbas R, Faramarzi M, Zarandi A, Moradi A, Tenenbaum HC, et al. Effects of enamel matrix derivative on nonsurgical management of peri-implant mucositis: a double-blind randomized clinical trial. Clin Oral Investig. Clinical Oral Investigations. 2017;21:2379-88. https://doi.org/10.1007/s00784-016-2033-7.

51. Salvi GE, Ramseier CA. Efficacy of patient-administered mechanical and/or chemical plaque control protocols in the management of peri-implant mucositis. A systematic review. J Clin Periodontol. 2015;42:S187-201. https://doi.org/10.1111/jcpe.12321. This paper underlines the importance of self-administrated oral hygine procedures.

52. De Siena F, Francetti L, Corbella S, Taschieri S, Del Fabbro M. Topical application of $1 \%$ chlorhexidine gel versus $0.2 \%$ mouthwash in the treatment of peri-implant mucositis. An observational study. Int J Dent Hyg. 2013;11:41-7. https://doi.org/10.1111/idh.12002.

53. Hallström H, Persson GR, Lindgren S, Olofsson M, Renvert S. Systemic antibiotics and debridement of peri-implant mucositis. A randomized clinical trial. J Clin Periodontol. 2012;39:574-81. https://doi.org/10.1111/j.1600-051X.2012.01884.x.

54. Wohlfahrt JC, Evensen BJ, Zeza B, Jansson H, Pilloni A, RoosJansåker AM, et al. A novel non-surgical method for mild periimplantitis - a multicenter consecutive case series. Int J Implant Dent. 2017;3. https://doi.org/10.1186/s40729-017-0098-y.

55. John G, Sahm N, Becker J, Schwarz F. Nonsurgical treatment of periimplantitis using an air-abrasive device or mechanical debridement and local application of chlorhexidine. Twelve-month follow-up of a prospective, randomized, controlled clinical study. Clin Oral Investig. 2015;19:1807-14. https://doi.org/10.1007/s00784-015-1406-7.

56. Schwarz F, Sculean A, Rothamel D, Schwenzer K, Georg T, Becker J. Clinical evaluation of an Er:YAG laser for nonsurgical treatment of peri-implantitis: a pilot study. Clin Oral Implants Res. 2005;16:44 52. https://doi.org/10.1111/j.1600-0501.2004.01051.x.

57.• Chambrone L, Wang H-L, Romanos GE. Antimicrobial photodynamic therapy for the treatment of periodontitis and peri-implantitis: an American Academy of Periodontology best evidence review. J Periodontol. 2018;89:783-803. https://doi.org/10.1902/jop.2017. 170172. This review summarizes the evidence on the use of photodynamic therapy to management peri-implant diseases.

58. Mettraux GR, Sculean A, Bürgin WB, Salvi GE. Two-year clinical outcomes following non-surgical mechanical therapy of peri- 
implantitis with adjunctive diode laser application. Clin Oral Implants Res. 2016;27:845-9. https://doi.org/10.1111/clr.12689.

59. Bassetti M, Schär D, Wicki B, Eick S, Ramseier CA, Arweiler NB, et al. Anti-infective therapy of peri-implantitis with adjunctive local drug delivery or photodynamic therapy: 12-month outcomes of a randomized controlled clinical trial. Clin Oral Implants Res. 2014;25:279-87. https://doi.org/10.1111/clr.12155.

60. Roos-Jansåker AM, Almhöjd US, Jansson H. Treatment of periimplantitis: clinical outcome of chloramine as an adjunctive to non-surgical therapy, a randomized clinical trial. Clin Oral Implants Res. 2017;28:43-8. https://doi.org/10.1111/clr.12612.

61. Estefanía-Fresco R, García-de-la-Fuente AM, Egaña-FernándezValderrama A, Bravo M, Aguirre-Zorzano LA. One-year results of a nonsurgical treatment protocol for peri-implantitis. A retrospective case series. Clin Oral Implants Res. 2019;30:70212. https://doi.org/10.1111/clr.13456.

62. Roccuzzo M, Grasso G, Dalmasso P. Keratinized mucosa around implants in partially edentulous posterior mandible: 10-year results of a prospective comparative study. Clin Oral Implants Res. 2016;27:491-6. https://doi.org/10.1111/clr.12563. This paper underlines the importance of the presence of keratined mucosa to reduce plaque acculumation and peri-implant softtissue recession in the long-term.

Publisher's Note Springer Nature remains neutral with regard to jurisdictional claims in published maps and institutional affiliations. 